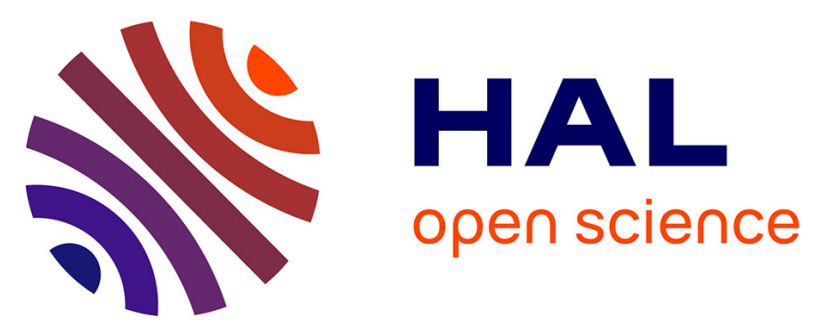

\title{
Effects of an Enhanced Heart Rate Reserve on Aerobic Performance in Patients with a Heart Transplant
}

Nathalie Ville, Alain Varray, Béatrice Mercier, Maurice Hayot, Bernard Albat, Karim Chamari, Christian Prefaut, Jacques Mercier

\section{- To cite this version:}

Nathalie Ville, Alain Varray, Béatrice Mercier, Maurice Hayot, Bernard Albat, et al.. Effects of an Enhanced Heart Rate Reserve on Aerobic Performance in Patients with a Heart Transplant. American Journal of Physical Medicine and Rehabilitation, 2002, 81 (8), pp.584 - 589. 10.1097/00002060200208000-00005 . hal-01622954

\section{HAL Id: hal-01622954 \\ https://hal.umontpellier.fr/hal-01622954}

Submitted on 22 Mar 2018

HAL is a multi-disciplinary open access archive for the deposit and dissemination of scientific research documents, whether they are published or not. The documents may come from teaching and research institutions in France or abroad, or from public or private research centers.
L'archive ouverte pluridisciplinaire HAL, est destinée au dépôt et à la diffusion de documents scientifiques de niveau recherche, publiés ou non, émanant des établissements d'enseignement et de recherche français ou étrangers, des laboratoires publics ou privés. 


\section{Authors:}

Nathalie S. Ville, PhD

Alain Varray, $\mathrm{PhD}$

Béatrice Mercier, $\mathrm{PhD}$

Maurice Hayot, MD, PhD

Bernard Albat, MD

Karim Chamari, PhD

Christian Préfaut, MD, PhD

Jacques Mercier, MD, PhD

\section{Affiliations: \\ From the Laboratoire de Physiologie et de Biomécanique de l'Exercice Musculaire, Rennes, France (NSV); the Laboratoire Sport, Performance, Santé, Montpellier, France (AV, BM); the Laboratoire de Physiologie des Interactions, Service de Physiologie Clinique, Montpellier, France $(\mathrm{MH}$, $\mathrm{KC}, \mathrm{CP}, \mathrm{JM})$, Service de Chirurgie Cardiovasculaire et Thoracique, Montpellier, France (BA).}

\section{Disclosures:}

Supported by a grant from the "Centre Hospitalo-Universitaire" (Contrat de recherche clinique DGS 950187).

\section{Correspondence:}

All correspondence and requests for reprints should be addressed to Nathalie Ville, PhD, Laboratoire de Physiologie et de Biomécanique de l'Exercice Musculaire, UFR.APS, Université Rennes 2-Haute Bretagne, CS 24414, Avenue Charles Tillon, 35044 Rennes cedex, France.

\section{Effects of an Enhanced Heart Rate Reserve on Aerobic Performance in Patients with a Heart Transplant}

\section{ABSTRACT}

Ville NS, Varray A, Mercier B, Hayot M, Albat B, Chamari K, Préfaut $C$, Mercier J: Effects of an enhanced heart rate reserve on aerobic performance in patients with a heart transplant. $A m \mathrm{~J}$ Phys Med Rehabil 2002;81:584-589.

Objective: The aim of this study was to investigate whether a high-intensity warm-up at the start of a graded, symptom-limited exercise test would enhance heart rate reserve and thus improve the aerobic performance of orthotopic heart transplant patients.

Design: Adrenal and cardiorespiratory responses were compared in 10 orthotopic heart transplant patients who performed two graded, symptom-limited exercise tests on an ergocycle.

Results: At the start of the graded, symptom-limited exercise test, high intensity increased the norepinephrine level more than usual intensity between rest and the third minute of exercise. This higher norepinephrine level was followed by a higher heart rate response from the fourth minute of exercise. Heart rate reserve was enhanced during high-intensity exercise, without any significant change in peak oxygen uptake.

Conclusions: This specific warm-up enhanced heart rate reserve during a graded, symptom-limited exercise test on an ergocycle. Mechanisms more important than limited heart rate reserve are involved in the limitation of exercise tolerance in orthotopic heart transplant patients.

Key Words: Cardiac Transplantation, Oxygen Uptake, Chronotropic Response, Exercise 
A hemodynamics nervation are a common finding after orthotopic heart transplantation (OHT). Heart rate reserve (HRR), which is peak heart rate (HR) minus the resting $\mathrm{HR}^{3}{ }^{3}$ is the most decreased cardiac parameter ${ }^{4}$ because of a high resting $\mathrm{HR}$ and a low peak HR. Moreover, it has been shown that the percentage of change in HR from rest to peak exercise is correlated with peak oxygen uptake $\left(\mathrm{V}_{2} ; r=\right.$ 0.60). ${ }^{5}$ Thus, HRR may affect aerobic power after OHT, but no causal relationship has been demonstrated to date. The factors that limit the exercise tolerance of heart transplant recipients are not yet well understood, but abnormal chronotropic response is generally cited as one of the explanations for the peak $\dot{V}_{2}$ limitation. ${ }^{6,7}$

Because HR response to exercise is delayed and reduced after heart transplantation, ${ }^{6,8-10}$ we hypothesized that a high workload $(50 \mathrm{~W})$ at the start of an incremental exercise test allowing the assessment of HRR and peak $\dot{\mathrm{V}}_{2}$ would increase catecholamine levels rapidly and markedly. We further speculated that after 6 min of exercising at this workload, the effects would be nearly optimal in terms of chronotropic response. The aim of this study was thus to investigate the ability of a specific warm-up $(50 \mathrm{~W})$ to enhance adrenal response, HR increase, and HRR during a symptom-limited exercise test and then to assess the effect on aerobic power.

\section{METHODS}

\section{Subjects}

Ten male OHT patients (age, 55 $\pm 2 \mathrm{yr}$; weight, $74.5 \pm 2.8 \mathrm{~kg}$; height, $173.6 \pm 1.2 \mathrm{~cm}$; postsurgery time, $31.6 \pm 6.6 \mathrm{mo}$ ) volunteered to participate in the study. None was involved in a rehabilitation program. Before surgery, their clinical status was class IV according to the New York Heart Association, with etiologies including dilated cardiomyopathy $(n=3)$ and ischemic cardiopathy $(n=7)$. After surgery, all patients were considered to be class I and were receiving triple-drug immunosuppressive therapy (cyclosporine, azathioprine, and steroid [average dose, $10 \mathrm{mg} /$ day]). None was receiving $\beta$-blocker agents or other therapies that could affect the chronotropic response. All were free of acute rejection, systemic infection, coronary artery disease, and peripheral vascular disease. Informed written consent was obtained from all patients, and the study was accepted by the hospital ethics committee (Comité de protection des personnes pour la recherche biologique No. 950187).

\section{Materials}

Exercise Testing. Each subject performed two different graded, symptom-limited exercise tests in random order on an electromagnetic cycle ergometer (Ergo-Metrics 900; Ergoline, Bitz, West Germany). Respiratory variables and gas exchanges were measured with a breath-by-breath automated metabolic system (CPX, Cardio2, Breeze; Medical Graphics, St. Paul, MN). ${ }^{11}$ During exercise, oxygen saturation was continuously determined with a pulse oximeter (Datex, Helsinki, Finland), and a 12-lead electrocardiograph (CPX, Cardio2, Breeze) was monitored for the measurement of HR. Finally, systolic and diastolic blood pressure were measured with a cuff blood pressure transducer (Ergoline).

\section{Cardiorespiratory Measurements.} We were principally interested in HR, which allowed the calculation of HRR (peak exercise HR - resting HR) and $\dot{\mathrm{V}}_{2}$. We also measured $\mathrm{CO}_{2}$ output $\left(\mathrm{V} \mathrm{CO}_{2}\right)$ to determine the respiratory exchange ratio $\left(\mathrm{VCO}_{2} / \mathrm{O}_{2}\right)$.
Circulating Catecholamine Analysis.

One of the 10 subjects did not agree to venous sampling. So in nine subjects, a venous catheter was inserted in a superficial forearm vein to allow sampling for measurement of epinephrine and norepinephrine concentrations. A three-way tap was placed on the catheter to allow rinsing with a syringe containing a mixture of heparin and physiologic saline (250 IU/ml) and blood sampling with a dry syringe after the catheter had been cleared of saline. Approximately $3 \mathrm{ml}$ of blood was placed in a tube (lithium heparin) containing reduced glutathione $(1.2 \mathrm{mg} / \mathrm{ml})$ to control catecholamine oxidation, centrifuged (3000 rpm for $10 \mathrm{~min}$ ) and stored at $-80^{\circ} \mathrm{C}$ for catecholamine analysis. Plasma catecholamine concentrations were determined by high-performance liquid chromatography (HPLC). ${ }^{12}$ The catecholamines were extracted by selective absorption to aluminum oxide (ChromsystemsHPLC-Kit; Waters Corp., Milford, MA) before the HPLC run. Aluminum oxide was briefly shaken up in extraction buffer $(50 \mu \mathrm{l})$, and then $1 \mathrm{ml}$ of plasma was added with $50 \mu \mathrm{l}$ of internal standard solution (600 pg of dihydroxybenzylamine). The aluminum oxide was washed three times, with brief centrifugation between washes. The catecholamines were extracted with $120 \mu$ l of elution buffer with brief shaking and then centrifuged (final centrifugation) at 2000 rpm for $1 \mathrm{~min}$. Then $50 \mu \mathrm{l}$ of sample eluent was injected into the HPLC column (Resolve 5- $\mu$ l spherical C18 HPLC column; Waters Corp.) and eluted with mobile phase. The flow rate was $1 \mathrm{ml} / \mathrm{min}$ at 2000 psi with a potential of $0.60 \mathrm{~V}$. The chromatogram was analyzed by computer integration (Baseline 815; Waters Corp.). Three assays were made for each sample, and the mean of these assays was taken for statistics. The error of measurement within sample was satisfactory (less than 5\%), similar to 
that found in a previous study of our group. ${ }^{13}$

\section{Protocol}

The order of the two exercise tests was randomized, and the subjects performed the two tests within a 2 -wk period. On the days of the experiment, patients arrived at the laboratory at the same hour in the morning and received standardized instructions as to the testing procedure. On day 1 , they underwent a complete physical examination and a resting electrocardiogram. Each patient then performed a graded, symptom-limited cycle exercise test. The second exercise test was performed on day 2. One of the tests had a usual intensity (UI) for warm-up (i.e., 20 W). ${ }^{11}$ The patient rested for $3 \mathrm{~min}$ while seated on the cycle and then, after a warm-up at $20 \mathrm{~W}$ for $3 \mathrm{~min}$, loads were increased $10 \mathrm{~W}$ each minute until exhaustion. The other test, with a high intensity (HI) warmup, was similar in that the patient rested for $3 \mathrm{~min}$ on the cycle. But the warm-up consisted of cycling at $50 \mathrm{~W}$ for $6 \mathrm{~min}$, with loads then increased $10 \mathrm{~W}$ each minute (in such a way that at the seventh minute, all patients were exercising at $60 \mathrm{~W}$ ) until exhaustion.

All cardiorespiratory values were recorded at rest, up to peak exercise, and during recovery, for the last 20 sec of every minute. Systolic and diastolic blood pressure were measured every 3 min up to the end of exercise.

Samples for catecholamines were taken at rest, at the third minute (which corresponded to the end of the usual starting workload), and at the sixth minute (which corresponded to the end of the HI starting workload) of the exercise test and at peak exercise. To minimize the intersubject variation, as seen in some studies, ${ }^{7,14}$ the concentrations of norepinephrine and epinephrine at the third and sixth minute of exercise were expressed by using the third- or sixth-minute exercise values minus resting value. $\Delta$ Catecholamines was also calculated between rest and peak exercise (peak exercise - resting values).

Indications for halting the exercise test before the appearance of a plateau $\mathrm{V}_{2}$ were as follows: (1) adverse symptoms: severe dyspnea, light-headedness and faintness, confusion, severe fatigue, or inability to maintain the pedaling frequency; (2) adverse signs: facial pallor, HR or blood pressure decrease (or failure of either to increase with increasing effort), or a rapid increase in systolic or diastolic blood pressure, or both, exceeding 210/115 mm Hg for a moderate intensity of exercise $(<60 \mathrm{~W})$; and (3) adverse electrocardiographic changes: frequent complex ventricular extrasystoles, ventricular tachycardia, sustained supraventricular tachycardia, second- or third-degree heart block, severe ST depression (horizontal or down sloping greater than $2 \mathrm{~mm}) .{ }^{15}$ A respiratory exchange ratio $>1.1$ and the inability to maintain the pedaling frequency despite the standardized encouragements of the experimenters were the criteria for verifying that the exercise tests were really symptom limited. ${ }^{11,15}$

\section{Statistical Analysis}

Values of all variables are expressed by the mean \pm SEM. Paired Student's $t$-tests were performed on resting $\mathrm{HR}$ and HRR. Resting and peak $\dot{V}_{O_{2}}$ were compared for statistical difference by using the same procedure. Submaximal HR time courses were compared by using a fully factorial repeated-measures design. When the $\mathrm{F}$ ratio was significant, the Tukey test was performed to identify differences. In addition, catecholamine values at rest and during exercise (norepinephrine and epinephrine values at 3 and $6 \mathrm{~min}$ ) and $\Delta$ norepinephrine and $\Delta$ epinephrine (peak exercise - resting values) were compared with the Wilcoxon's signed rank test. SigmaStat (Jandel Scientific, Costa Madre, CA) and SYSTAT
(SPSS Inc., Chicago, IL) software was used for these statistical analyses. The level of significance for all analyses was $P \leq 0.05$.

\section{RESULTS}

During the graded exercise tests, none of the OHT patients developed decreases in oxygen saturation of more than 4\%, adverse signs or symptoms, or electrocardiogram changes such as severe ST segment depression, tachycardia, or atrial fibrillation. All stopped the exercise test because of leg fatigue and pain. The duration of the two tests was not significantly different $(12.4 \pm 1 \mathrm{~min}$ and $12.3 \pm 0.9 \mathrm{~min}$ for $\mathrm{HI}$ and UI, respectively), and most of the patients were able to exercise longer after the HI warm-up; only two patients exercised for less than $10 \mathrm{~min}$.

There was no significant difference for epinephrine response during exercise (at 3 and $6 \mathrm{~min}$ ) or for $\Delta$ epinephrine $(112.3 \pm 37.9 \mathrm{pg} / \mathrm{ml}$ for $\mathrm{HI}$ vs. $54.9 \pm 43.6 \mathrm{pg} / \mathrm{ml}$ for UI). Concerning norepinephrine concentration, during $\mathrm{HI}$, norepinephrine values at 3 and 6 min were significantly lower than $\Delta$ norepinephrine (peak resting value; $P<0.05$ ). During UI, norepinephrine at $3 \mathrm{~min}$ was significantly lower than norepinephrine at 6 min $(P<0.05)$, but it was not significantly different from $\Delta$ norepinephrine. Norepinephrine at $3 \mathrm{~min}$ was significantly higher during $\mathrm{HI} v$ s. UI $(P<0.05 ;$ Fig. 1$)$. There was no significant difference for $\Delta$ norepinephrine between HI and UI (Fig. 1).

At rest, cardiorespiratory values were similar for the two tests (Table 1). HR was significantly higher in HI than in UI from the fourth to sixth minute of exercise (Fig. 2). HRR was significantly higher during $\mathrm{HI} v s$. UI $(P<0.05)$, in contrast to peak $\dot{\mathrm{V}}_{2}$ (Fig. 3).

\section{DISCUSSION}

This study shows that, during a symptom-limited exercise test, a spe- 


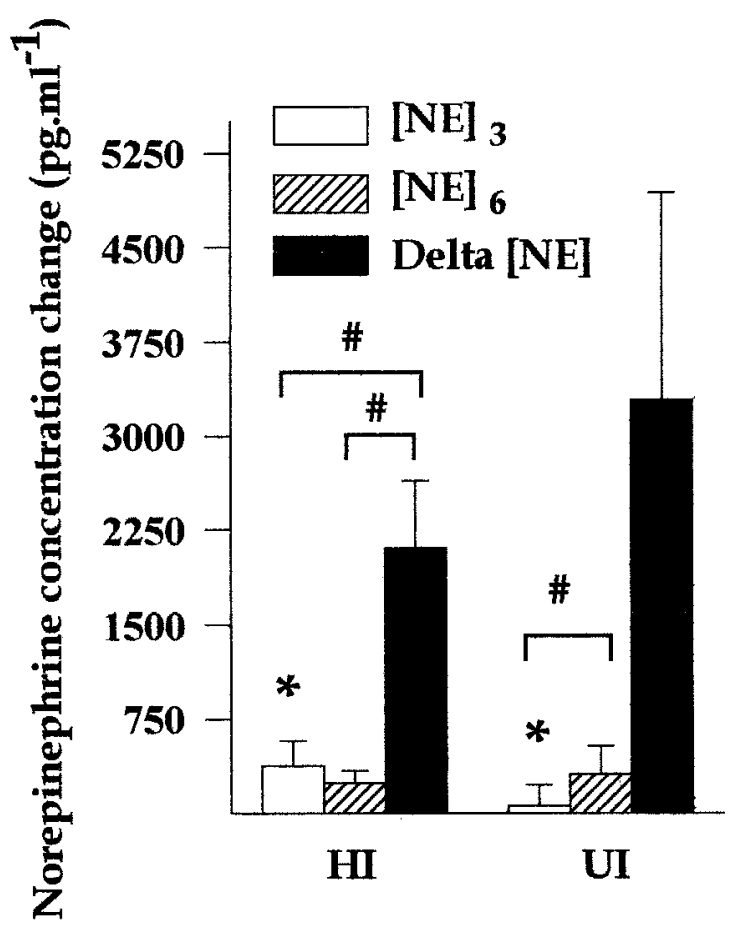

Figure 1: Norepinephrine concentration changes from rest to the third minute of exercise $\left([\mathrm{NE}]_{3}=\right.$ third minute of exercise value - resting value) to the sixth minute of exercise $\left([\mathrm{NE}]_{6}=\right.$ sixth minute of exercise value - resting value) and to peak exercise (Delta $[\mathrm{NE}]=$ peak exercise value - resting value) for the high-intensity warm-up test ( $\mathrm{HI}$ warm-up $=50 \mathrm{~W}$ for $6 \mathrm{~min}$ ) and the usualintensity warm-up test (UI warm-up $=20 \mathrm{~W}$ for $3 \mathrm{~min}$ ). ${ }^{\star} P<0.05$ between $\mathrm{HI}$ and UI; \#P<0.05 within the group. The other compared values were not significantly different.

cific warm-up enhances the submaximal HR and HRR in OHT patients. This enhancement of HRR is not associated with a significant enhancement of peak $\dot{\mathrm{V}}_{2}$.

The HR values at rest and during submaximal and peak exercise in the UI condition are typical of the denervated heart, i.e., a delayed and gradual increase in HR with the onset of exercise $e^{6,8,9}$ and a low peak HR, ${ }^{6,9}$ attaining only $78.1 \pm 3.2 \%$ of predicted maximal
HR. In normal subjects, the HR increase observed at the onset of exercise is initially caused by the withdrawal of vagal tone. ${ }^{16,17}$ The literature notes that during exercise in heart transplant patients, the observed HR change is closely linked to the level of circulating catecholamines, ${ }^{2,14}$ with a linear relationship during constant-load exercise between HR and norepinephrine increments. ${ }^{14}$ Nevertheless, during HI, because of the higher and longer starting

\section{TABLE 1}

Cardiorespiratory values for the two tests

\begin{tabular}{lccccc}
\hline & \multicolumn{2}{c}{ Rest } & & \multicolumn{2}{c}{ Peak Exercise } \\
\cline { 2 - 3 } \cline { 5 - 6 } & HI & UI & & HI & UI \\
\hline $\mathrm{HR}\left(\right.$ beats $\left.\cdot \mathrm{min}^{-1}\right)$ & $101.1 \pm 3$ & $101.1 \pm 3$ & & $143 \pm 5$ & $136 \pm 5$ \\
$\dot{\mathrm{V}} \mathrm{O}_{2}\left(\mathrm{ml} \cdot \mathrm{kg}^{-1} \cdot \mathrm{min}^{-1}\right)$ & $4.8 \pm 0.4$ & $5 \pm 0.2$ & & $23.2 \pm 1.6$ & $23 \pm 1.8$ \\
\hline
\end{tabular}

HI, high-intensity workload; UI, usual-intensity workload; HR, heart rate; $\dot{\mathrm{V}}_{2}$, oxygen uptake.

workload compared with UI, the increase in norepinephrine was significantly higher at the third minute of exercise, whereas the HR response was significantly increased from the fourth to sixth minute.

First, because norepinephrine at 3 and 6 min during HI were not different, we can speculate that the norepinephrine concentration was stable because it was adapted to the level of the intensity $(50 \mathrm{~W})$. In UI, in contrast, the norepinephrine level increased between the third and sixth minute of exercise proportionally to the increase in exercise intensity. Indeed, at the sixth minute of exercise, the work load was the same in $\mathrm{HI}$ and UI $(50 \mathrm{~W})$, and there was no difference in norepinephrine concentrations between the two tests at this moment. Second, concerning the chronotropic response, at the third minute of HI, HR showed only a tendency to be higher than in UI. Moreover, at the sixth minute of $\mathrm{HI}, \mathrm{HR}$ was significantly higher. This result can be explained by a delay between the release of norepinephrine, its fixation on the endomyocardial $\beta$ receptors, and the subsequent chronotropic response. This hypothesis would explain in part why, during the first phases of recovery, a rapid decrease in norepinephrine concentration was observed without the same change in HR in OHT patients. ${ }^{14}$ Furthermore, the gain in HR at the start of exercise during $\mathrm{HI}$ seemed to persist until the end of exercise, as indicated by the significantly higher HRR in HI $v s$. UI.

This study shows that it was possible to increase HRR in heart transplant patients. This enhanced HRR was not followed by higher aerobic power, because peak $\dot{\mathrm{V}}_{2}$ was not statistically different between $\mathrm{HI}$ and UI. However, HRR may still be linked to the limitation in aerobic performance, because the percentage of change in HR from rest to peak exercise is correlated with peak $\dot{\mathrm{V}}_{2}$, and patients with a high percentage of 


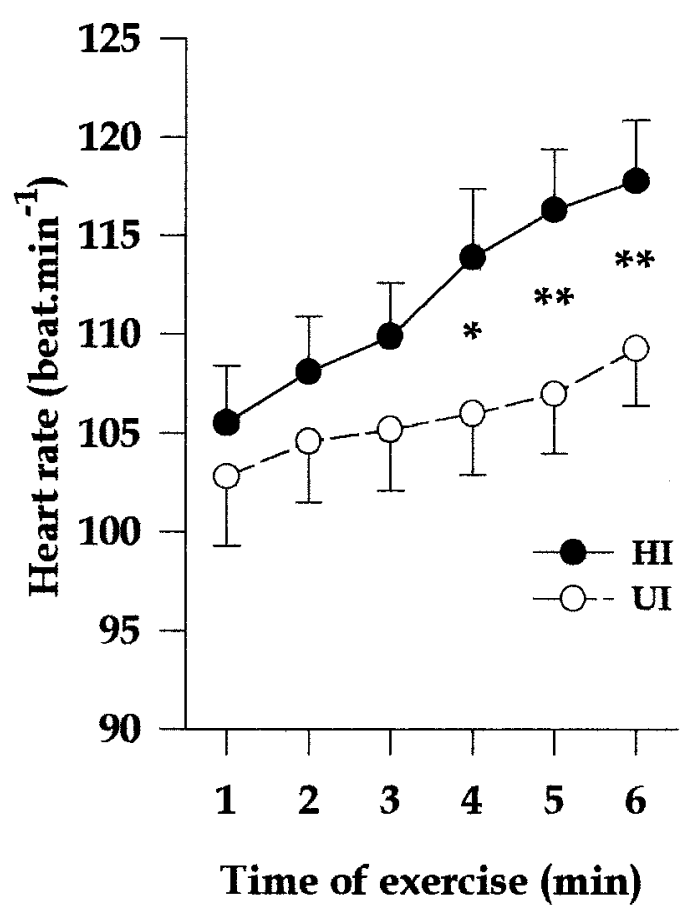

Figure 2: Time course of heart rate during submaximal exercise. ${ }^{*} P<0.05$ and ${ }^{\star \star} P<0.01$ between the high-intensity warm-up test $(H /$ warm-up $=50 \mathrm{~W}$ for $6 \mathrm{~min}$ ) and the usual-intensity warm-up test ( $U /$ warm-up $=20 \mathrm{~W}$ for $3 \mathrm{~min})$. change in HR $(>40 \%)$ have a higher peak $\dot{V}_{2}$ than patients with a low percentage of change $(<40 \%){ }^{5} \mathrm{Be}$ cause OHT patients generally have a low HRR, ${ }^{4}$ in our study the mean increase in this variable during $\mathrm{HI}(7$ beats/min) was high when expressed as a relative value, i.e., as a percentage $(20 \%)$. These results are in agreement with previous data from our

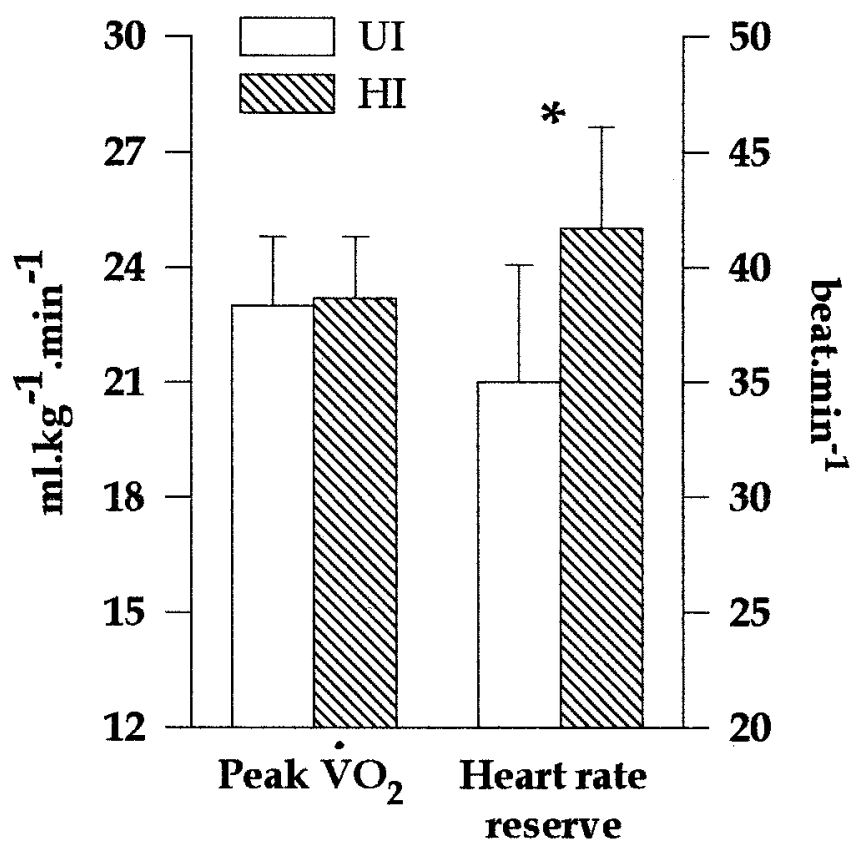

Figure 3: Peak oxygen uptake $\left(\mathrm{V}_{2}\right)$ and heart rate reserve (peak exercise resting heart rate) for the high-intensity warm-up test $(H /$ warm-up $=50 \mathrm{~W}$ for $6 \mathrm{~min}$ ) and the usual-intensity warm-up test (UI warm-up $=20 \mathrm{~W}$ for $3 \mathrm{~min}$ ). ${ }^{*} P$ $<0.05$ between $\mathrm{HI}$ and $\mathrm{UI}$. group that were obtained during a longitudinal study, which found a peak HR increase with postsurgery time, without an increase in peak $\dot{\mathrm{V}}_{2} \cdot{ }^{15}$ This peak $\dot{\mathrm{V}}_{2}$ was symptom limited in the two exercise conditions, at $77.4 \pm 3.2 \%$ and $76.4 \pm$ $5.7 \%$ of predicted in HI vs. UI. Because the relation between cardiac output and oxygen consumption is linear in OHT patients, ${ }^{18}$ this indicates that whatever the HR, cardiac output remained unchanged. Some studies have suggested that the inability of the denervated heart to achieve the same HR level as the innervated heart may be responsible for the decreased oxygen uptake observed in OHT patients., ${ }^{6,79}$ Our data, in agreement with a study by Jensen et al., ${ }^{18}$ indicate that factors other than the limited and sluggish increase in HR may influence the exercise limitation in OHT patients. First, we and other authors recently demonstrated that the abnormal pulmonary diffusion capacity found in many OHT patients was associated with the peak $\dot{\mathrm{V}}_{2} \cdot{ }^{11,20}$ Second, the exaggerated skeletal deconditioning of OHT patients caused by extended periods of inactivity both before and after surgery ${ }^{7}$ may be implicated. Third, a detrimental effect of immunosuppressive therapy on mitochondrial skeletal muscle respiration has been reported in rats. ${ }^{21-23} \mathrm{~A}$ detrimental effect of immunosuppressive therapy on vasodilatory capacity (already impaired in humans after heart transplantation) has also been suggested. ${ }^{10,24,25}$ Fourth, Jensen et al. ${ }^{18}$ showed that OHT patients are able to maintain their oxygen-carrying capacity within normal range, and persistent skeletal muscle abnormalities have been found in these patients. ${ }^{26,27}$ Furthermore, the maximal arteriovenous oxygen difference seems to be low in heart transplant recipients. ${ }^{19}$ These last studies seem to indicate a peripheral limitation during exercise. In our study, all patients stopped exercise because of leg 
pain and fatigue. Moreover, because our results indicate a cardiac output response adapted to the level of exercise, the hypothesis of a peripheral limitation seems to be increasingly pertinent.

In conclusion, our study clearly demonstrates that a specific warm-up can enhance HRR during a graded, symptom-limited exercise test in OHT patients. This warm-up resulted in a higher increase in catecholamine levels during submaximal exercise, which was followed, after a slight delay, by an enhancement of HR. However, because aerobic power, as determined by peak $\dot{V}_{2}$ values, was similar between the high warm-up protocol and the usual one, whereas the HRR was $20 \%$ enhanced with the HI, more important mechanisms are probably involved in the limitation of exercise tolerance in these patients. Although it is worthwhile in itself to try to normalize HR response to exercise by using a specific warm-up, studies are needed to further investigate the role of pulmonary and especially peripheral factors that limit exercise capacity. A better understanding of these factors is essential for the prescription of physical training programs that can optimize exercise tolerance.

\section{ACKNOWLEDGMENTS}

We thank the medical teams for their technical help and all the patients who participated in this study.

\section{REFERENCES}

1. Pflugfelder P, McKenzie F, Kostuk W: Hemodynamic profiles at rest and during supine exercise after orthotopic cardiac transplantation. Am J Cardiol 1988;61: 1328-33

2. Pope SE, Stinson EB, Daughters GT, et al: Exercise response of the denervated heart in long-term cardiac transplant recipients. Am J Cardiol 1980;46:213-8

3. Brooks GA, Fahey TD, White TP: $E x$ - ercise Physiology. Human Bioenergetics and Its Applications, ed 2. Mountain View, CA, Mayfield Publishing Company, 1996, pp 156-8

4. Badenhop DT: The therapeutic role of exercise in patients with orthotopic heart transplant. Med Sci Sports Exerc 1995; 27:975-85

5. Kemp DL, Jennison SH, Stelken AM, et al: Association of resting heart rate and chronotropic response. Am $J$ Cardiol 1995;75:751-2

6. Savin WM, Haskell WL, Schroeder JS, et al: Cardiorespiratory responses of cardiac transplant patients to graded, symptom-limited exercise. Circulation 1980; 62:55-60

7. Ehrman J, Keteyian S, Fedel F, et al: Cardiovascular responses of heart transplant recipients to graded exercise testing. J Appl Physiol 1992;73:260-4

8. Cerretelli P, Grassi B, Colombini A, et al: Gas exchange and metabolic transients in heart transplant recipients. Respir Physiol 1988;74:355-71

9. Degré SG, Niset GL, De Smet JM, et al: Cardiorespiratory response to early exercise testing after orthotopic cardiac transplantation. Am J Cardiol 1987;60:926-8

10. Braith RW, Edwards DG: Exercise following heart transplantation. Sports Med 2000;30:171-92

11. Ville N, Mercier JG, Varray A, et al: Exercise tolerance in heart transplant patients with altered pulmonary diffusion capacity. Med Sci Sports Exerc 1998;30: $339-44$

12. Hjemdahl P: Catecholamine measurements by high-performance liquid chromatography. Am J Physiol 1984; 247(1 Pt 1):E13-20

13. Hue O, Le Gallais D, Boussana A, et al: Catecholamine, blood lactate and ventilatory responses to multi-cycle-run blocks. Med Sci Sports Exerc 2000;32: 1582-6

14. Périni R, Orizio C, Gamba A, et al: Kinetics of heart rate and catecholamines during exercise in humans. Eur $J \mathrm{Appl}$ Physiol 1993;66:500-6

15. Mercier JG, Ville N, Wintrebert $P$, et al: Influence of post-surgery time after cardiac transplantation on cardiorespiratory responses during exercise. Med Sci Sports Exerc 1996;28:171-5

16. Robinson BF, Epstein SE, Beiser GD, et al: Control of heart rate by the auto- nomic nervous system. Circ Res 1966;19: $400-11$

17. Rowell LB, O'Leary DS: Reflex control of the circulation during exercise: chemoreflexes and mechanoreflexes. J Appl Physiol 1990;69:407-18

18. Jensen RL, Yanowitz FG, Crapo RO: Exercise hemodynamics and oxygen delivery measurements using rebreathing techniques in heart transplant patients. Am J Cardiol 1991;68:129-33

19. Kao AC, Van Tright P, Shaeffer-McCall GS, et al: Allograft diastolic dysfunction and chronotropic incompetence limit cardiac output response to exercise two to six years after heart transplantation. J Heart Lung Transplant 1995;14: $11-22$

20. Al-Rawas OA, Carter R, Stevenson $\mathrm{RD}$, et al: Exercise intolerance following heart transplantation: the role of pulmonary diffusing capacity impairment. Chest 2000;118:1661-70

21. Hokanson JF, Mercier JG, Brooks GA: Cyclosporine A decreases skeletal muscle mitochondrial respiration in vitro. Am J Respir Crit Care Med 1995;151:1848-51

22. Kimberg DV, Loud AV, Weiner J: Cortisone-induced alterations in mitochondrial function and structure. J Cell Biol 1968;37:63-79

23. Mercier JG, Hokanson JF, Brooks GA: Effects of cyclosporine A on skeletal muscle mitochondrial respiration and endurance time in rats. Am J Respir Crit Care Med 1995;151:1532-6

24. Andreassen AK, Kirkeboen KA, Gullestad L, et al: Effect of heart transplantation on impaired peripheral microvascular perfusion and reactivity in congestive heart failure. Int J Cardiol 1998; 65:33-40

25. Andreassen AK, Kvernebo K, Jorgensen B, et al: Exercise capacity in transplant recipients: relation to impaired endothelium-dependent vasodilatation of the peripheral microcirculation. $\mathrm{Am}$ Heart J 1998;136:320-8

26. Stratton JR, Kemp GJ, Daly RC, et al: Effects of cardiac transplantation on bioenergetic abnormalities of skeletal muscle in congestive heart failure. Circulation 1994;8:1624-31

27. Mettauer B, Lampert E, Petitjean P, et al: Persistent exercise intolerance following cardiac transplantation despite normal oxygen transport. Int $J$ Sports Med 1996;17:277-86 